\title{
Attachment: What is it and Why is it so Important?
}

\author{
Miriam Crouch
}

\begin{abstract}
This article examines attachment; viewing attachment as a continuum from secure attachment relationships through to attachment disorders. The article outlines theoretical bases in attachment, the implications of healthy secure attachment and that of insecure attachment in educational settings, suitable interventions and the importance of prevention of attachment disorders.
\end{abstract}

Keywords: attachment, protection, relationships

\section{Research paper}

\section{WHAT IS ATTACHMENT?}

Attachment is a reciprocal process by which an emotional connection develops between an infant and his/her primary caregiver. It influences the child's physical, neurological, cognitive and psychological development. It becomes the basis for development of basic trust or mistrust, and shapes how the child will relate to the world, learn, and form relationships throughout life (Association for Treatment and Training in the Attachment of Children (ATTACh), 2015). The time considered crucial for the development of attachment bonds is in the first three years of life, and this bond influences relationships throughout the life span. An attachment disorder occurs due to traumatic disruption or other interferences with the caregiver-child bond during the first years of life (ATTACh, 2015). Attachment issues could be seen as a continuum, with disorders at the extreme end, then a variety of attachment-related difficulties and lesser behavioural and emotional problems, through to secure attachment.

According to Bowlby (1974), those with histories of secure attachment will have positive expectations regarding relationships with others, an inclination to be closely involved with others and the social and emotional capacities that promote social competence (Scroufe, 2005). Infants who receive sensitive and responsive caregiving will come to represent themselves as worthy of care, others as trustworthy and the world as a safe place. In contrast, infants who do not receive sensitive caregiving will come to represent themselves as unworthy of care, others as untrustworthy and the world as unsafe (Fivush, 2006). An attachment disorder can distort future stages of development and impact a person's cognitive, neurological, social and emotional functioning. It may also increase risk of other serious emotional and behavioural problems (ATTACh, 2015).

\section{Theoretical Bases}

Attachment theory has been described as the dominant approach to understanding early social development. Bowlby (1907-1990) is regarded as an important theorist, and is famous for his pioneering work in attachment theory. The most important tenet of attachment theory is that an infant needs to develop a relationship with at least one primary caregiver for their successful social and emotional development. In his 1951 monograph for the World Health Organisation, Maternal Care and Mental Health, Bowlby put forward the hypothesis that infants and children need to experience an intimate and warm relationship with their mother; relationships that are continuous and which bring enjoyment and satisfaction to both. He posited that the lack of such a relationship may have significant and irreversible mental health consequences (Bowlby, 1951). Bowlby's work on attachment caused a virtual revolution and many changes in policy and procedures for children's hospitals and residential homes. Another pioneer in this field was Hungarian paediatrician, Emmi Pikler. Emmi ran a home for children and recommended building trust, respecting the infant and the importance of touch to build this trusting relationship. Over time, orphanages were abandoned in favour of foster care or family-style homes in most developed countries (Rutter, 2008).

Bowlby was a mentor for, and later became a colleague of Mary Ainsworth (1913-1999). Ainsworth was the first researcher in attachment to categorise different patterns of attachment. Ainsworth is credited with establishing the 'Strange Situation' along with 
her colleague, Wittig, in 1965. Ainsworth herself was the first to find difficulties in fitting all infant behaviour into the three classifications used in her Baltimore study. It was Mary Main, a colleague of Ainsworth, along with her colleague Judith Solomon who identified and empiricised a fourth category of attachment patterns, the disorganised form of attachment. It is accepted now that there are four types of attachment: secure, and three types of insecure attachment - avoidant, ambivalent and disorganised.

Attachment theory has had an impact on the procedures followed by the family court and the system is now taking into account the multiple relationships within a family. Societal changes have been influenced by attachment theory; nowadays there are fewer orphanages and more family homes, fewer closed and more open adoptions, and hospitals have open-door policies for primary caregivers. Professionals are aware of the impact maternal depression and stress can have on bonding and the development of attachment with children. Changes in maternity care have shifted from believing best practice was to remove the baby from the mother straight after birth to clean the baby and let the mother rest, towards encouraging skin to skin contact, which is considered to be a precursor to start the bonding process of attachment.

\section{IMPLICATIONS OF SOUND ATTACHMENT FOR CHILDREN'S DEVELOPMENT}

Early caregiving has a long-lasting impact on development, the ability to learn, capacity to regulate emotions and form satisfying relationships (Siegel, 2012). The ideal attachment relationship is that of a secure attachment. Children who are securely attached to their caregiver have a relationship based on love, consistency, affection and sensitivity (Obadina, 2013). Bowlby (1974) proposed the idea of the secure base. This is where children are given the ability to explore, yet parents provide the secure base for children to return to if they become scared or hurt. This secure base allows the child to feel comfortable to explore and learn. Children with a secure attachment to their carer generally feel confident that the carer will reliably provide reassurance and comfort when the child needs it; they are free to explore the wider environment because they are assured that they can return to their carer as and when necessary (Wilkens, 2012). The consistency of care, empathy and commitment of a parent allows the child to progress steadily through developmental stages, steadily building vital skills of self-regulation, understanding and competence (Kagan, 2004). Carers who are psychologically available and predictable, sensitive and accepting allow children to develop a good psychological understanding of themselves, others and relationships (Howe, Dooley \& Hinings, 2000).

Children who can regulate their own emotions achieve more academically in schools (Gottman, 1997). Secure attachments support mental processes which enable the child to regulate emotions, reduce fear, attune to others, have self-understanding and insight, empathy for others and appropriate moral reasoning (Bath Spa University, 2014). Children with secure attachment are able to trust and rely on teachers to meet their needs. As a result, they feel confident to form meaningful relationships with others, to make the most of learning opportunities, to engage in productive activities, problem-solve and explore the wider world. These children are emotionally resilient and self-aware (Bath Spa University, 2014).

\section{THE NATURE OF DISORDERED ATTACHMENT AND HOW IT AFFECTS LEARNING AND DEVELOPMENT}

The quality of care provided by caregivers varies. Attachment figures that are emotionally unavailable and unresponsive are just as likely to cause anxiety and distress as those who are physically absent. Attachment disorders occur among children who have failed to develop a secure selective attachment to their primary caregiver or caregivers, and who have experienced inconsistent, insensitive, inadequate and or abusive and frightening care (Pearce, 2009). There is no one factor that creates an attachment disorder, nor do any factors cause an attachment disorder in all children (Swanson Cain, 2006). Attachment styles can overlap; while some children fall solely into one category, others may fall into a mixture of categories (Levendosky, Huth-Bocks \& Bogat, 2011). This can have implications in the assessment and diagnosis of an attachment disorder.

A child's initial dependence on others for protection provides the experiences and skills to help a child cope with frustrations, develop self-confidence and pro-social relationships - all qualities necessary to promote positive engagement with learning (Bath Spa University, 2014). Research has inextricably linked attachment to school readiness and school success (Geddes, 2006). Insecure attachment has a significant impact on a child's emotional regulation. Children with attachment disorders have difficulty connecting to others and managing their own emotions. This results in a lack of trust and self-worth, a fear of getting close to anyone, anger, and a need to be in control. A child with an attachment disorder feels unsafe and alone, and this can cause them to display an array of difficult behaviours as they try to gain control of their environment and the people in it. To be able to engage in learning, a pupil needs to be 
able to take risks, to learn new things and face new challenges. A good learner needs to be able to manage frustration and anxiety, have good self-esteem, be willing to take risks and be able to ask for help when needed (Bath Spa University, 2014) - characteristics fostered in the context of secure attachment.

\section{ASSESSMENT/DIAGNOSIS}

The most common and empirically-supported method for assessing attachment in infants and toddlers (12 months-20 months) is the Strange Situation Protocol, developed by Ainsworth as a result of her careful, in-depth observations of infants with their mothers in Uganda. The Strange Situation is not a diagnostic tool but a way of researching the type of attachment disorder, and the resulting attachment classifications are not clinical diagnoses'.

Currently, there is no specific, validated tool for diagnosing attachment disorders after infancy. An evaluation could be made on the basis of a diagnostic interview, direct observation of interaction with parents or caregivers, caregiver/teacher checklists, details about the patterns of behaviour over time, examples of the behaviour in a variety of situations, known history and questions about the home and living situation since birth, behavioural observations and an evaluation of parenting and caregiving styles and abilities. Medical and psychiatric examinations of symptomatic children are appropriate so as to rule out physical causes or differential mental illness diagnoses which might account for the child's symptoms and behaviours.

\section{INTERVENTION FOR THE FAMILY}

Attachment theory is a well-established theory, supported by extensive research in which there is general agreement that attachment problems can be difficult to mend. Similar to many other disorders, early intervention is paramount and the earlier an attachment issue is picked up, the more likelihood of interventions being successful. It seems clear from the work on attachment stability that attachment and resilience can and does change. Exciting findings from recent research show that resilience can be learned. Problems of attachment are hard, although not impossible to treat. The earlier children get help, the greater their chances of successful treatment. A child will not grow out of an attachment problem, therefore treatment is critical. Without treatment, attachment disorders do not get better. As well as support to develop positive relationships, students would benefit from being taught how to regulate emotions, and develop resilience through a positive attitude and optimism.
Families need to be provided with emotional, financial and practical support in order for them to access appropriate intervention for themselves and their children (Dawson, Ashman \& Carver, 2000). Interventions must focus on the needs of the entire family and must include therapeutic activities that can focus on behaviour change and help families resolve difficult issues, and promote the health and wellbeing of the whole family (Obadina, 2013). Attempts must be made by professionals to meet the parent's own emotional needs and improve their caring skills, as research into infant mental health by Weatherston highlighted that parents cannot adequately meet their infants' basic needs until their own basic needs are met (Howe, 2005). Identifying issues with attachment early is paramount as interventions aimed at improving the quality of care in children's early years may be more productive.

Often, but not always, conditions of social disadvantage cluster together making it difficult to discern which ones might influence the formation of attachments. The factors that can contribute to problems with the parent forming a secure attachment relationship with their child, such as maternal depression, mental health issues, addictions, relationship problems, and financial issues, need to be recognised by all of the agencies who come in contact with these parents and either have counsellors or advocates who help parents by providing support and guidance or refer the parent to agencies that specialise in these societal problems.

Dysfunctional parenting is a major contributing factor in attachment disorders, and support organisations need to focus on teaching parenting skills which in turn will help to prevent attachment disorders. Currently in New Zealand there are some quality evidence-based parenting programmes such as Incredible Years that promote attuned attentive caregiving. The Incredible Years Parenting Programme is a programme that is known to be successful with a variety of cultures and socioeconomic groups.

Drugs and alcohol are particularly devastating in their power to overwhelm parents' maternal drive to care for their children (Kagan, 2004). Parents who are dependent on drugs and alcohol can be prone to erratic mood-swings, delusions, paranoia, loss of memory and sometimes loss of consciousness; leaving them unable to meet their children's needs or keep them safe (Barnard, 2007). Domestic violence can have a direct impact on parents' self-esteem, so while victims concentrate on appeasing the perpetrator, they are unable to protect their children from getting caught up in the abuse; such behaviour 
affects the child's ability to form attachments (Levendosky et al., 2011). Domestic violence often co-exists with other risk factors like economic resources and lack of education, which puts further strain on the mother-child relationship (Dawson et al., 2000). Also, if parents are able to comprehend and overcome their own childhood experiences of abuse or neglect, realise the impact of their behaviour on their children and are willing to work with professionals, this will greatly improve their child's future prospects (Obadina, 2013). As mentioned previously, families need to be provided with emotional, financial and practical support in order for them to access appropriate interventions.

\section{INTERVENTIONS AT SCHOOL/EARLY CHILDHOOD SERVICES}

Interventions need to start with whole centre/school practices of safety, reliability and predictability. Only when children are safe enough and calm enough can we begin to address their insecurities through consistent caring relationships which understand their profound uncertainties (Geddes, 2006). In early childhood education there is a foundational emphasis on attachment and strong responsive, reciprocal caregiving for children when in out-of-home care. This is established in the early childhood curriculum 'Te Whariki'. Teachers can provide important attachments for children (Bergin \& Bergin, 2009; Riley, 2010). Close and supportive relationships with teachers have demonstrated the potential to mitigate the risk of negative outcomes for children who may otherwise have difficulty succeeding in school (Driscoll \& Pianta, 2010).

Effective treatment of attachment disordered children necessarily involves education of caregivers and professionals who work with the child regarding the care and support requirements of these children (Pearce, 2009). The relationship between the teacher and student is pivotal. Successful intervention starts with the teacher building a positive relationship with the student and then providing a predictable environment with clear boundaries. From this secure foundation other areas such as developing social skills, building self-esteem, emotional literacy, autonomy and self-identity can be developed (Bath Spa University, 2014). Recent research has highlighted the importance of the quality of the relationship between the teacher and student, and then between the home and school environments. By strengthening relationships and creating more positive home and school environments we remove barriers to engagement and improve students' chances to achieve at school and beyond (Ministry of Education, 2015).
Research on attachment suggests that a relational rather than behavioural framework for supporting children's behaviour is more effective (Bergin \& Bergin, 2009). A behavioural model relies heavily on rewards to modify behaviour and this does not always work with students who have attachment difficulties. A relational framework promotes universal well-being, learning and behaviour, and can be especially helpful with children who have attachment difficulties or other vulnerabilities (Bath Spa University, 2014), as it relies heavily on the development and maintenance of positive relationships.

Positive Behaviour for Learning School-Wide takes the approach that opportunities for learning and achievement increase if the school environment is positive and supportive, and a structured environment and classroom schedule helps a child to feel safe. The classroom teacher should provide a stable, predictable routine and children should be prepared for changes in the schedule in advance if possible. There should be expectations that are consistently clear. Students should be consistently taught desired behaviours. Teachers should ensure good behaviours are acknowledged every time, and undesirable behaviours are responded to in a fair and equitable way (Ministry of Education, 2015).

Children with attachment disorders may feel the need to control and manipulate adults around them, which can make teaching such a child difficult at times. The teacher needs to maintain control of their own emotions, to deliver consequences consistently but to try not to show frustration or anger. An important factor when supporting children with difficult behaviours can be self-care. An informed staff who understand attachment difficulties can be a great source of support and encouragement to the classroom teacher; therefore whole-staff professional development, as well as external support agencies and services, is essential to providing understanding of attachment disorders. Ideally there also needs to be an effective form of communication developed between home and school to benefit the child. It is well-evidenced that partnership between home and school is central to effective intervention (Hornby, 2011).

\section{PREVENTION}

There is still some debate as to whether attachment disorders can be cured but very few would argue that prevention is better than looking for a cure, and attachment disorders can be prevented. Despite the information available, attachment disorders remain difficult to diagnose and treat, although recent brain development and resiliency research have furthered our understanding of this critical area. Research affirms that emphasis needs to be placed on good quality parenting, education and direct prevention 
of attachment disorders through supporting early attachment relationships, understanding the role of attachment in early childhood and school, and providing wrap-around social support services (Dawson, Ashman \& Carver, 2000).

Promotion of healthy prenatal development must focus on generating public awareness, outreach and intervention programmes, minimising maternal stress during pregnancy and reducing foetal exposure to alcohol and drugs (Dawson, Ashman \& Carver, 2000). New mothers should be routinely screened for postpartum depression, and parents and young children exposed to trauma should be able to access dyadic therapy (Cohen, Oser \& Quigley, 2012). Dyadic therapy is an evidence-based, effective and empirically-validated treatment for attachment disorders and early trauma. Mothers with mental health problems should be given appropriate psychological and medical intervention at prenatal screening stage and this should become part of regular baby checkups, and education materials relating to behavioural development should be made readily available (Dawson et al., 2000). Home visits should be compulsory for at-risk families, as it is crucial to the assessment of parent-child interactions (Obadina, 2013). The importance of home visits has been acknowledged in New Zealand with the introduction of the 'Well Child Tamariki Ora' programme, which offers education, support and guidance to parents from birth to just before school entry.

Support agencies could possibly help reduce attachment disorders in future generations; attachment patterns are passed from parent to child and attachment disorders are transmitted intergenerationally. Attachment theory states that caregiving patterns, and the degree to which parents are able to respond and be sensitive to their children, are related to their mental representations of attachment experiences with their own parents (George \& Solomon, 2008). By teaching parenting skills and the importance of developing secure attachment, this could prevent attachment disorders from being passed down through generations. By identifying and supporting parents in the highrisk category and providing them with parenting programmes, education and support, these agencies are not only preventing possible attachment disorders but could also be preventing cases of child abuse.

\section{SUMMARY}

Attachment theory has become one of the dominant theories used today in the study of infant and toddler behaviour and in the fields of infant mental health, treatment of children, and related fields. It is clear from research that early experiences are most significant in shaping later outcomes for children. However, there are still many parents who are unaware that their parenting behaviours can affect their children in such drastic ways. An area for society to focus on is the promotion of ongoing education and training to raise this public awareness.

Although attachment theory has been around for many years, it appears to now be utilised more in policies and decision-making and many more professionals are aware of the implications of insecure attachment. In summary, it appears that focus needs to continue to be placed towards further research in preventing insecure attachment and early interventions to encourage healthy, secure attachments.

\section{REFERENCES}

Association for Treatment and Training in the Attachment of Children (ATTACh) (2015). Resources. Retrieved from https://attach.org

Barnard, M. (2007). Drug addiction and families. London: Jessica Kingsley Publishing.

Bath Spa University (2014). An introduction to attachment and the implications for learning and behaviour. Retrieved from https://www.bathspa.ac.uk/Search?q=attachment

Bergin, C., \& Bergin, D. (2009). Attachment in the classroom. Educational Psychology Review, 21, 141-170.

Bowlby, J. (1951). Maternal care and mental health. A report prepared on behalf of the World Health Organization as a contribution to the United Nations programme for the welfare of homeless children. Retrieved from http://apps.who.int/iris/bitstream/10665/40724/1/ WHO_MONO_2_(part1).pdf

Bowlby, J. (1974). The making and breaking of affectional bonds. London: Tavistock.

Cohen, J., Oser, C., \& Quigley, K. (2012). Making it happen: Overcoming barriers to providing infantearly childhood mental health. Retrieved from http://www.zerotothree.org/public-policy/federalpolicy/early-child-mental-health-final-singles.pdf

Dawson, G., Ashman, S.B., \& Carver, L.J. (2000). The role of early experience in shaping behavioural and brain development and its implications for social policy. Development and psychopathology, 12, 695-712.

Driscoll, K., \& Pianta, R.C. (2010). Banking time in head start: Early efficacy of an intervention designed to promote supportive teacher-child relationships. Early Education and Development, 21(1), 38-27. 
Fivush, R. (2006). Scripting attachment: Generalised even representations and internal working models. Attachment and Human Development, 8, 283289.

Geddes, H. (2006). Attachment in the classroom: The links between children's early experience, emotional wellbeing and performance in school. London: Worth Publishing.

George, C., \& Solomon, J. (2008). The caregiving system: A behavioural-system approach to parenting. In J. Cassidy \& P.R. Shaver (Eds.), Handbook of attachment: Theory, research and clinical applications (pp. 833-856). New York: Guilford Press.

Gottman, J. (1997). Raising an emotionally intelligent child. The heart of parenting. NY: Fireside.

Hornby, G (2011). Parental involvement in childhood education. Building effective school-family partnerships. New York: Springer

Howe, D. (2005). Child abuse and neglect: Attachment, development and intervention. Basingstoke: Palgrave Macmillan

Howe, D., Dooley, T., \& Hinings, D. (2000). Assessment and decision-making in a case of child neglect and abuse using an attachment perspective. Child and Family Social Work, 5, 143-155.

Kagan, R. (2004). Rebuilding attachments with traumatized children: Healing from losses, violence, abuse and neglect. Binghamton, NY: Haworth Press Inc.

Levendosky, A., Huth-Bocks, A., \& Bogat, C. (2011). The influence of domestic violence on the development of the attachment relationship between mother and young child. Psychoanalytic Psychology, 28(4), 512-27.

Ministry of Education (2015). Positive behaviour for learning. Retrieved from http://pb4l.tki.org.nz/

Obadina, S. (2013). Understanding attachment in abuse and neglect: Implications for child development. British Journal of School Nursing, 8(6), 290-295.

Pearce, C. (2009). A short introduction to attachment and attachment disorder. London, UK: Jessica Kingsley Publishers.

Riley, P. (2010). Attachment theory and teacher student relationships. London: Routledge.
Rutter M. (2008). Implications of attachment theory and research for childcare policies. In J. Cassidy, P.R. Shaver (Eds.), Handbook of attachment: theory, research and clinical applications (pp. 958-74). New York and London: Guilford Press.

Scroufe, L. A. (2005). Attachment and development: A prospective, longitudinal study from birth to adulthood. Attachment and Human Development, 7, 349-367.

Siegel, D. (2012). The Developing Mind: How relationships and the brain interact to shape who we are. New York: Guilford Press.

Swanson Cain, C. (2006). Attachment disorders: Treatments strategies for traumatized children. Maryland, USA: Rowman \& Littlefield Publishers Inc.

Wilkens, D. (2012). Disorganised attachment indicates child maltreatment: How is this link useful for child protection social workers? Journal of Social Work Practice, 26(1), 15-30.

\section{AUTHOR PROFILE}

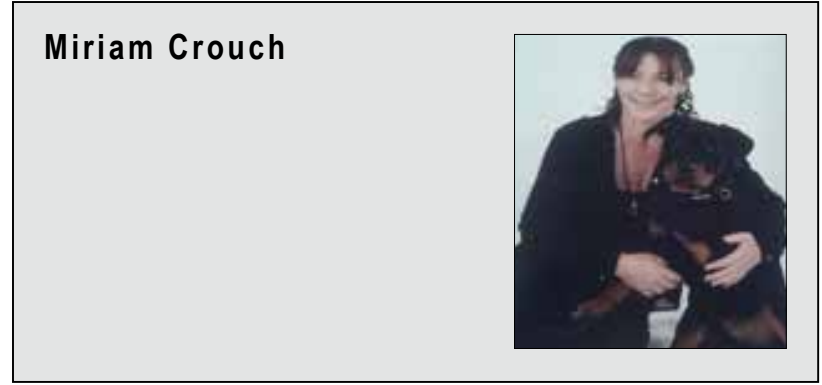

Miriam Crouch is currently employed by the Ministry of Education, working in the Severe Behaviour Team. Miriam completed a Masters in Education, a Diploma in Child Protection Studies, a Postgraduate Certificate in Educational Psychology and a Postgraduate Diploma in Specialist Teaching (RTLB). Miriam Crouch's professional background includes experience working as a primary school teacher, working in a CYFs supervised group home, and work as a specialist teacher.

\section{Email:}

zerotolerance@clear.net.nz 